\title{
Glial-neuronal signaling mechanisms underlying the neuroinflammatory effects of manganese
}

\author{
Katriana A. Popichak', Maryam F. Afzali², Kelly S. Kirkley ${ }^{3}$ and Ronald B. Tjalkens ${ }^{1 *}$ (D)
}

\begin{abstract}
Background: Exposure to increased manganese $(\mathrm{Mn})$ causes inflammation and neuronal injury in the cortex and basal ganglia, resulting in neurological symptoms resembling Parkinson's disease. The mechanisms underlying neuronal death from exposure to $\mathrm{Mn}$ are not well understood but involve inflammatory activation of microglia and astrocytes. Expression of neurotoxic inflammatory genes in glia is highly regulated through the NF-KB pathway, but factors modulating neurotoxic glial-glial and glial-neuronal signaling by $\mathrm{Mn}$ are not well understood.

Methods: We examined the role of NF-KB in Mn-induced neurotoxicity by exposing purified microglia, astrocytes (from wild-type and astrocyte-specific IKK knockout mice), and mixed glial cultures to varying Mn concentrations and then treating neurons with the conditioned media (GCM) of each cell type. We hypothesized that mixed glial cultures exposed to $\mathrm{Mn}(0-100 \mu \mathrm{M})$ would enhance glial activation and neuronal death compared to microglia, wild-type astrocytes, or IKK-knockout astrocytes alone or in mixed cultures.
\end{abstract}

Results: Mixed glial cultures treated with 0-100 $\mu \mathrm{M}$ Mn for $24 \mathrm{~h}$ showed the most pronounced effect of increased expression of inflammatory genes including inducible nitric oxide synthase (Nos2), Tnf, CCl5, II6, C Cr2, II16, and the astrocyte-specific genes, C3 and CCI2. Gene deletion of IKK2 in astrocytes dramatically reduced cytokine release in Mn-treated mixed glial cultures. Measurement of neuronal viability and apoptosis following exposure to Mn-GCM demonstrated that mixed glial cultures induced greater neuronal death than either cell type alone. Loss of IKK in astrocytes also decreased neuronal death compared to microglia alone, wild-type astrocytes, or mixed glia.

Conclusions: This suggests that astrocytes are a critical mediator of Mn neurotoxicity through enhanced expression of inflammatory cytokines and chemokines, including those most associated with a reactive phenotype such as CCL2 but not C3.

Keywords: Neuroinflammation, Manganism, Astrocyte, Glial-glial communication, Glial-neuronal communication, $\mathrm{NF}-\mathrm{kB}, \mathrm{CCL} 2$

\section{Background}

Manganese $(\mathrm{Mn})$ is an essential trace element primarily acquired through diet. However, increased exposures in juveniles and adults lead to inflammation and neuronal injury in the cortex and basal ganglia that can cause irreversible neurodegeneration associated with cognitive and motor deficits. Sources of excess Mn exposure include

\footnotetext{
* Correspondence: ron.tjalkens@colostate.edu

'Department of Environmental and Radiological Health Sciences, College of Veterinary Medicine and Biomedical Sciences, Colorado State University, 1680 Campus Delivery, Physiology Building, Room 101, Fort Collins, CO 80523-1680, USA

Full list of author information is available at the end of the article
}

soy-based infant formula [1], well water [2], and industrial activities such as mining [3] and welding [4]. Activation of astrocytes and microglia in response to $\mathrm{Mn}$ neurotoxicity can lead to overproduction of neurotoxic levels of reactive oxygen and nitrogen species (ROS, RNS) [5], as well as inflammatory cytokines such as TNF [6]. Additionally, astrocytes concentrate Mn through plasma membrane divalent metal transports, which increase oxidative stress and decrease their capacity for neuronal trophic support by affecting key metabolic coupling pathways such as glutamate uptake and glutathione synthesis $[7,8]$. The combination of enhanced

(C) The Author(s). 2018 Open Access This article is distributed under the terms of the Creative Commons Attribution 4.0 International License (http://creativecommons.org/licenses/by/4.0/), which permits unrestricted use, distribution, and 
inflammatory gene expression and decreased trophic support may therefore cause a reactive phenotype that promotes neuronal injury.

A number of studies have demonstrated that $\mathrm{Mn}$-induced glial activation is exacerbated by glial-derived pro-inflammatory factors that damage neurons. Data from our laboratory recently demonstrated that NF- $\mathrm{KB}$ signaling in microglia plays an essential role in inflammatory responses in Mn toxicity by regulating cytokines and chemokines that amplify the activation of astrocytes [6]. Although this demonstrates that nuclear factor kappa B (NF-kB) signaling in microglia is essential to inflammatory activation of astrocytes, subsequent effects of astrocytes on microglia and ultimately on neuronal cell death are less well understood. It was reported that $\mathrm{Mn}$ exposure induces activation of microglia and signs of dystrophy including increased iron-mediated oxidative stress in the substantia nigra of non-human primates [9], as well as microglia-induced degeneration of dopaminergic neurons in rats [10]. Previous studies from our laboratory and others demonstrated that expression of inducible nitric oxide synthase (iNOS/NOS2) and NO production in astrocytes causes injury to surrounding neurons in Mn-exposed mice [11-14]. NOS2 and many other pro-inflammatory factors are highly regulated in glial cells by NF-kB, consistent with data reporting that the NF-kB-mediated pro-inflammatory cytokines CCL2, CCL5, and TNF released by astrocytes are associated with $\mathrm{Mn}$ neurotoxicity in in vitro studies of murine glia $[5,15,16]$.

However, only recently has research begun to establish how the communication between both glial cell types mediates Mn-induced neuronal injury [17]. The astrocyte-specific chemokine, CCL2, is regulated by NF-kB and induces microglial activation in a surgery-induced cognitive dysfunction and neuroinflammatory model, suggesting not only that astrocytes and microglia communicate during stress and injury, but also that NF-kB-mediated factors contribute to glial inflammation. NF- $\mathrm{kB}$ is activated in glia in response to $\mathrm{Mn}$, oxidative stress, and other neurotoxic exposures $[15,16,18]$. We recently reported that NF- $\mathrm{kB}$ activation in microglia amplifies the inflammatory response of astrocytes to $\mathrm{Mn}$ toxicity, resulting in overproduction of inflammatory cytokines and chemokines such as TNF, IL1, and IL6 [6]. However, it remains to be determined which NF-kB-regulated inflammatory signaling molecules in astrocytes modulate the inflammatory response of microglia, as well as the effect of this signaling on neuronal injury.

We therefore examined the role of NF- $\mathrm{B} B$ in Mn-induced neurotoxicity by exposing pure microglia, astrocytes (from wild-type and astrocyte-specific IKK/NF-KB knockout mice), and mixed glial cultures to varying concentrations of $\mathrm{Mn}$ and then treating neurons with the resultant glial-conditioned media (GCM) of each cell type. We hypothesized that $\mathrm{Mn}$ would enhance expression of inflammatory cytokines in mixed cultures of astrocytes and microglia to a greater extent than in either cell type alone and would similarly increase neuronal cell death. We measured expression of NF-KB-regulated inflammatory genes by qPCR in glial cells, as well as levels of secreted cytokines in GCM from both WT or IKK KO astrocytes and microglia using spotted array-based ELISA. Mn exposure enhanced expression of multiple inflammatory cytokines and chemokines in mixed glial cultures, which was inhibited by pharmacologic inhibition or genetic inhibition of NF- $\mathrm{kB}$. Additionally, Mn-stimulated GCM increased neuronal apoptosis, which was attenuated by inhibition of NF- $\mathrm{KB}$ in astrocytes, suggesting that activation of this signaling pathway in astrocytes is a critical mediator of glial reactivity and neuronal injury from $\mathrm{Mn}$ through release of cytokines and chemokines that amplify activation of microglia.

\section{Materials and methods \\ Materials}

All general chemical reagents including $\mathrm{MnCl}_{2}$ and antibiotics were purchased from Sigma Aldrich (St. Louis, $\mathrm{MO})$. Fluorescent antibodies and dyes were purchased from Life Technologies (Carlsbad, CA). Cell culture medium was acquired from Hyclone (Logan, UT) or Gibco (Life Technologies, Carlsbad, CA). For immunofluorescence studies and flow cytometric experimentation and live-cell imaging of primary neurons, Annexin

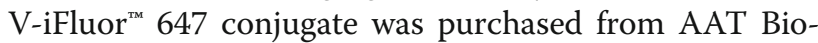
quest (Sunnyvale, CA), and Propidium Iodide and Caspase-3/7 Green were purchased from Life Technologies (Carlsbad, CA).

\section{Primary glial and neuronal isolation}

Cortical glia and neurons were isolated from 1-day-old $\mathrm{C} 57 \mathrm{Bl} / 6$ or transgenic mouse pups according to procedures described previously $[6,19]$, and purity confirmed through immunofluorescence staining using antibodies against GFAP and IBA1 [20]. Mixed glial cultures were also established from astrocyte-specific IKK2 knockout mice, which were generated in our laboratory by crossing mice expressing a loxP-targeted (floxed) Ikk2 allele [21] with mice expressing the human Gfap promoter driving expression of cre recombinase [22]. Progeny were bred to homozygosity for the floxed-Ikk2 allele, and both male and female littermates from the F4 generation were utilized for cell isolations. Briefly, pups were euthanized by decapitation under isofluorane anesthesia, and cortices (astrocytes) were rapidly dissected out, and meninges removed. Tissue was subject to digestion with Dispase $(1.5 \mathrm{U} / \mathrm{ml})$, and a complete media change $24 \mathrm{~h}$ after plating to remove non-glial cell types from glial cultures and glia from neuronal cultures. Glial cultures were maintained at $37{ }^{\circ} \mathrm{C}$ and $5 \% \mathrm{CO}_{2}$ in minimum essential media supplemented with $10 \%$ heat-inactivated fetal bovine serum and a penicillin $(0.001 \mathrm{mg} / \mathrm{ml})$, 
streptomycin $(0.002 \mathrm{mg} / \mathrm{ml})$, and neomycin $(0.001)$ antibiotic cocktail (PSN). Neuronal cultures were maintained at $37^{\circ} \mathrm{C}$ and $5 \% \mathrm{CO}_{2}$ in neurobasal media supplemented with HEPES, B27, and PSN. Cell media was changed $24 \mathrm{~h}$ prior to all treatments. All animal procedures were approved by the Colorado State University Institutional Animal Care and Use Committee and were conducted in accordance with published $\mathrm{NIH}$ guidelines. Neuro-2a cells (N2A) were cultured as previously described [23].

\section{Treatments and glial-conditioned media experiments}

Glia were treated with $\mathrm{MnCl}_{2}$ (solubilized in saline) (0$100 \mu \mathrm{M}$ ) for $8 \mathrm{~h}$ similarly to methods and experimentation previously described [6]. In brief, prior to mRNA assessment or conditioned media experiments, glia were seeded onto six-well tissue culture plates at approximately $3 \times 10^{5}$ cells per well, grown to confluence and treated with saline or $100 \mu \mathrm{M} \mathrm{MnCl}_{2}$ (in $2 \mathrm{ml}$ total of cell culture medium adequate for growth/health of glia and survival/health of neurons; see the "Materials and methods" section) for $8 \mathrm{~h}$. To inhibit NF- $\mathrm{kB}$ signaling in glia, cells seeded in six-well plates were treated with $5 \mu \mathrm{M}$ Bay 11-7082 (Bay11; Sigma) or the vehicle dimethyl sulfoxide (DMSO; Sigma) at 0.05\% in complete media for $3 \mathrm{~h}$. Exposure to Bay11 or DMSO for $3 \mathrm{~h}$ had no effect on cell viability. Media was removed prior to $8 \mathrm{~h}$ treatment with Saline or $\mathrm{MnCl}_{2}$. Conditioned media (denoted GCM for mixed glia-conditioned media,
ACM for astrocyte-conditioned media, and MCM for microglia-conditioned media) were pooled per treatment and centrifuged at $800 \times g$ for $10 \mathrm{~min}$ to remove detached cells. N2As were seeded in six-well tissue culture plates at $1 \times 10^{5}$ cells per well for flow cytometry experiments or $5 \times$ $10^{3}$ cells per well of 96-well tissue culture plate for Presto Blue Viability Assay $24 \mathrm{~h}$ prior to $48 \mathrm{~h}$ exposure to conditioned media. Primary neurons were seeded in four-well chamber slides for live-cell imaging at $1 \times 10^{5}$ cells per well and $2 \times 10^{5}$ cells per well of a 96-well tissue culture plate for Presto Blue Viability Assay 10 days prior to $48 \mathrm{~h}$ exposure to conditioned medium. N2As and primary neurons were then assessed for viability and cell death markers.

\section{Real-time RT-PCR and qPCR array analysis}

Confluent mixed glia, purified astrocytes, or purified microglia were treated with $\mathrm{MnCl}_{2}(0-100 \mu \mathrm{M})$ for $8 \mathrm{~h}$ prior to RNA isolation. RNA was isolated using the RNEasy Mini kit (Qiagen, Valencia, CA), and purity and concentration were determined using a Nanodrop ND-1000 spectrophotometer (NanoDrop Technologies, Wilmington, DE). Following purification, RNA (250-1000 ng) was used as template for reverse transcriptase (RT) reactions using the iScript RT kit (BioRad, Hercules CA). The resulting cDNA was immediately profiled for mRNA expression according to the 2- $\Delta \Delta C T$ method [24]. Primer sequences for all genes profiled are provided in Table 1.

Table 1 Primer table. Primer sequences of measured genes in qPCR experiments

\begin{tabular}{|c|c|c|c|}
\hline Gene & Accession no. & Primer sequence $\left(5^{\prime}-3^{\prime}\right)$ & Length (bp) \\
\hline \multirow[t]{2}{*}{ Nos2 } & NM_010927.3 & For: TCA CGC TTG GGT CTT GTT & 149 \\
\hline & & Rev: CAG GTC ACT TTG GTA GGA TाT & \\
\hline \multirow[t]{2}{*}{ Tnfa } & NM_013693.3 & For: CTT GCC TGA TTC TTG CTT CTG & 140 \\
\hline & & Rev: GCC ACC ACT TGC TCC TAC & \\
\hline \multirow[t]{2}{*}{$111-\beta$} & NM_008361.3 & For: GCA GCA GCA CAT CAA CAA G & 90 \\
\hline & & Rev: CAC GGG AAA GAC ACA GGT AG & \\
\hline \multirow[t]{2}{*}{$\mathrm{CCl} 2$} & NM_011331.2 & For: TTAAAAACCTGGATCGGAACCAA & 121 \\
\hline & & Rev: GCATTAGCTTCAGATTTACGGGT & \\
\hline \multirow[t]{2}{*}{$\mathrm{CCl} 5$} & NM_013653.3 & For: GCT GCT TTG CCT ACC TCT CC & 104 \\
\hline & & Rev: TCG AGT GAC AAA CAC GAC TGC & \\
\hline \multirow[t]{2}{*}{$11-6$} & NM_031168.1 & For:CTG CAA GAG ACT TCC ATC CAG & 131 \\
\hline & & Rev:AGT GGT ATA GAC AGG TCT GTT GG & \\
\hline \multirow[t]{2}{*}{$\beta$-actin } & NM_007393.3 & For: GCT GTG CTA TGT TGC TCT AG & 117 \\
\hline & & Rev: CGC TCG TTG CCA ATA GTG & \\
\hline \multirow[t]{2}{*}{ Hprt } & NM_013556.2 & For: TCA GTC AAC GGG GGA CAT AAA & 142 \\
\hline & & Rev: GGG GCT GTA CTG CTT AAC CAG & \\
\hline \multirow[t]{2}{*}{ C3 } & NM_009778.3 & For: GAG CGA AGA GAC CAT CGT ACT & 83 \\
\hline & & Rev: TCT TTA GGA AGT CTT GCA CAG TG & \\
\hline \multirow[t]{2}{*}{ Ccr2 } & XM_011243064.2 & For: ATC CAC GGC ATA CTA TCA ACA TC & 89 \\
\hline & & Rev: TCG TAG TCA TAC GGT GTG GTG & \\
\hline
\end{tabular}




\section{Presto Blue viability assay}

N2A cells (5000 cells per well) or primary neurons $(2 \times$ $10^{5}$ cells/well) were grown or plated on 96-well plates for $24 \mathrm{~h}$ or 10 days, respectively, before treatment with GCM. After $48 \mathrm{~h}$, cells were imaged using the PrestoBlue Cell viability reagent (Life Technologies, Carlsbad, CA) per the manufacturer's protocol.

\section{Spotted protein array ELISA assays}

Measurement of cytokines in glia-conditioned media (resultant from treatments for mRNA expression profiling of glia) was sampled from glia prior to application on neurons and stored at $-80^{\circ} \mathrm{C}$. Stored media was thawed, and cytokines were measured using a custom mouse 7-plex ELISA (Q-Plex ${ }^{\text {Tw }}$ Mouse Cytokine Arrays, Quansys Biosciences, Logan, UT) according to manufacturer instructions and imaged on a ChemiDoc XRS (Life Science Research, Hercules, CA) to capture images. Levels of cytokines and chemokines were calculated from standard curves using Q-View imaging software (Quansys Biosciences, Logan, UT).

\section{RNA interference}

RNA interference (siRNA, small interfering RNA) oligonucleotides were purchased from Integrated DNA Technologies (IDT DNA, Coralville, IA). RNAi duplexes were designed against splice common variants of the target gene and were validated using a dose-response assay with increasing concentrations of the suspended oligo (900-1200 ng/ml) using a standard scrambled dicer substrate RNA (DsiRNA) as control. RNAi oligonucleotides were transfected using the TransIT-X2 delivery system (Mirus Bio, Madison, WI) $48 \mathrm{~h}$ before $100 \mu \mathrm{M} \mathrm{MnCl}{ }_{2}$ treatment. Separate siRNA systems were used to ensure specific knockdown of $\mathrm{Ccl} 2$ and $\mathrm{C} 3$ mRNA. The Ccl2 dsiRNA duplex sequences are $\left(5^{\prime} \rightarrow 3^{\prime}\right)$ UGAAGCUAAUGCAUCCACUACCUTT; UAAACAAUA CCUUGGAAUCUCAAACAC (IDT DsiRNA; denoted siCcl2). The C3 dsiRNA duplex sequences are $\left(5^{\prime} \rightarrow 3^{\prime}\right)$ UAAUAAAGCUUCAGUUGUAUUUCAA; UUGAAAUAC AACUGAAGCUUUAUUAGA (IDT DsiRNA; denoted siC3).

\section{Flow cytometry}

The percent of Annexin- $\mathrm{V}$ positive (+) and Propidium Iodide positive $(+)$ in neuroblastoma (N2A) cultures before and after treatment with or without conditioned media or $\mathrm{MnCl}_{2}$ for $48 \mathrm{~h}$ followed by flow cytometric analysis as described [6]. Briefly, cells were labeled using Annexin- $V$ and Propidium Iodide (PI) at room temperature for $1 \mathrm{~h}$. After labeling, the cells were washed twice in incubation buffer and resuspended at a final volume of $500 \mu \mathrm{L}$ of PBS and stored at $37{ }^{\circ} \mathrm{C}$ until analysis. Flow cytometry was performed on a Beckman Coulter CyAn ADP flow cytometer operated with Summit Software for data collection at
Colorado State University's Flow Cytometry Core Facility. All further data analysis was done utilizing FlowJo software (version 10.1; FlowJo, Ashland, OR).

\section{Statistical analysis}

Experiments were performed in triplicate, with replicates consisting of independent cultures using a minimum of $(n$ $=4$ ) four plates or cover slips per replicate study. Comparison of two means was performed by Student's $t$ test, while comparison of three or more means was performed using one-way ANOVA while those consisting of comparison of three or more among the genetic variations of wild-type and knock-out treatment groups followed the Tukey-Kramer multiple comparison post hoc test using Prism software (v6.0 h, Graphpad Software, Inc., San Diego, CA). For all experiments, data was reported as standard error mean $( \pm$ S.E.M) and $P<0.05$ was considered significant, although the level of significance was often much greater (" $P<0.05$; ${ }^{* * *} P<0.01$; ${ }^{* * * *} P<0.001$; ${ }^{* * * * *} P<0.0001$ ).

\section{Results \\ $\mathrm{MnCl}_{2}$ exposure induces increased inflammatory gene expression in mixed glial cultures}

To assess inflammatory gene expression following exposure to $\mathrm{MnCl}_{2}$, mixed primary glial cultures containing astrocytes and microglia, pure astrocytes, or pure microglia were treated for $24 \mathrm{~h}$ prior to profiling expression of inflammatory genes by qPCR. Mn exposure enhanced expression of inducible nitric oxide synthase (Nos2) and multiple inflammatory cytokines and chemokines, including the astrocyte-specific inflammatory complement factor, $C 3$, as well as $T n f, C c l 2$, and its receptor Ccr2, Ccl5, Il6, and Il13. These genes showed dose-dependent expression in mixed glia, with maximal gene expression at $100 \mu \mathrm{M} \mathrm{MnCl}_{2}$ (Fig. 1a). Pure astrocyte cultures (Fig. 1b) showed less increase in gene expression compared to mixed glia. Purified cultures of microglia (Fig. 1c) displayed less gene expression compared to either pure astrocytes or mixed glial cultures.

\section{Glia-conditioned media from mixed glial cultures containing both microglia and astrocytes causes more severe neuronal cell death than astrocyte-conditioned media or microglia-conditioned media}

To determine whether $\mathrm{MnCl}_{2}$ exposure causes the release of soluble neurotoxic factors from glia, cultures of mixed glia, pure astrocytes, or pure microglia were treated with 0-100 $\mu \mathrm{M} \quad \mathrm{MnCl}_{2}$ for $24 \mathrm{~h}$ and the resultant glia-conditioned media (GCM) added to cultured neurons (Fig. 2). Conditioned media from mixed glia (GCM) treated with $100 \mu \mathrm{M}$ significantly decreased neuronal viability following $24 \mathrm{~h}$ incubation in culture and was further decreased at $48 \mathrm{~h}$ for the $100 \mu \mathrm{M}$ treatment group (Fig. 2a, left panel). Neuronal cell death following $48 \mathrm{~h}$ exposure to 

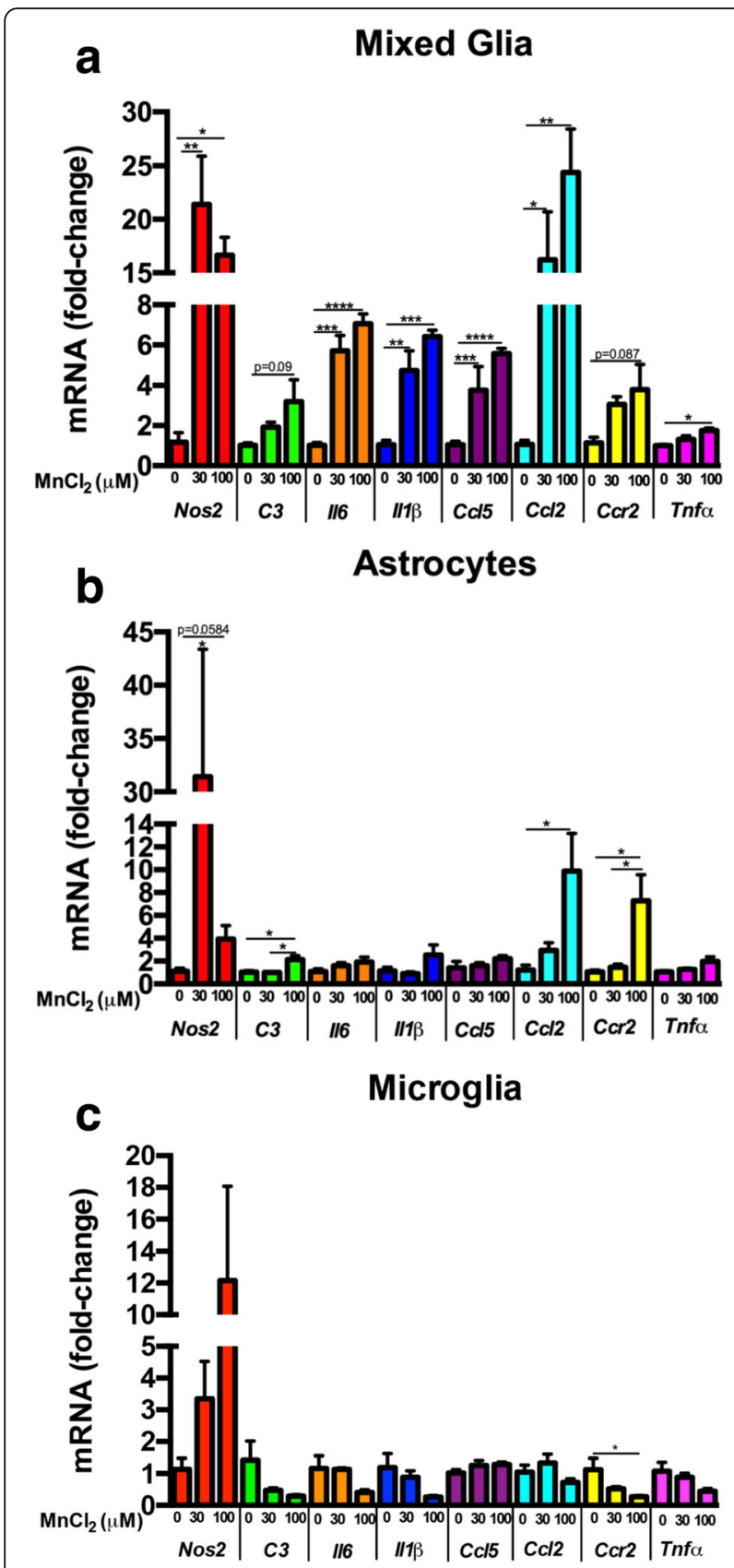

Fig. 1 Manganese-induced expression of neuroinflammatory genes in mixed glial cultures and in purified cultures of astrocytes and microglia. Inflammatory gene expression exhibited an overall dose-dependent increase in $\mathbf{a}$ mixed glia and $\mathbf{b}$ pure astrocytes and both dose-dependent increases in some genes and decreases in astrocyte-specific $\mathrm{C} 3, \mathrm{CCl}$, and $\mathrm{C} C \mathrm{r} 2$ in c pure microglia. One-way ANOVA analyses performed. Data depicted as \pm S.E.M. ${ }^{*} P<0.05 ;{ }^{* *} P<0.01 ;{ }^{* * *} P<0.001 ;{ }^{* * * *} P<0.0001$ ( $n \geq 4$ per treatment group; across $\geq 3$ independent experiments)

$100 \mu \mathrm{M} \mathrm{MnCl}{ }_{2}$-treated conditioned media was greater for GCM $(\sim 30 \%$ decreased viability $)$ than for either astrocyte-conditioned media (ACM) (Fig. 2b, left panel; $15 \%$ decreased viability) or microglia-conditioned media (MCM), which did not induce significant cell death despite a trend toward decreasing viability. Flow cytometric analyses of neuronal cells treated for $48 \mathrm{~h}$ with GCM-100 $\mu \mathrm{M}$ $\mathrm{MnCl}_{2}$ indicated an increase in apoptotic neurons, based on staining for Annexin V and Propidium Iodide (PI), as indicated by quantification bar graphs and depicted in representative histograms. GCM-100 $\mu \mathrm{M} \mathrm{MnCl}_{2}$ resulted in 38.98\% Annexin-positive and 38.81\% PI-positive neurons (Fig. 2c, top panel), as depicted in representative histograms (Fig. 2d, top panel) compared to AMC-100 $\mu \mathrm{M}$ $\mathrm{MnCl}_{2}$ which resulted in $11.11 \%$ Annexin-positive and 11.13\% PI-positive neurons (Fig. 2c, d, middle panel), while MCM-100 $\mu \mathrm{M} \mathrm{MnCl}_{2}$ resulted in $16.2 \%$ Annexin-positive and $17.66 \%$ PI-positive neurons (Fig. 2c, d, bottom panel).

\section{Pharmacologic inhibition of NF-kB decreases} inflammatory gene expression in mixed glia and in purified astrocytes following exposure to $\mathrm{MnCl}_{2}$

To determine the function of NF- $\mathrm{kB}$ in $\mathrm{MnCl}_{2}$-induced inflammatory gene expression in mixed glia or pure astrocytes, we pretreated cell cultures with the NF- $\mathrm{kB}$ inhibitor, Bay 11-7082 (Bay-11) [(E)- 3-(4-methylphenyl) sulfonylprop-2-enenitrile], or the vehicle control, dimethylsulfoxide (DMSO), prior to treatment with $100 \mu \mathrm{M} \mathrm{MnCl}_{2}$. Pretreatment with Bay-11 broadly suppressed expression of inflammatory genes in mixed glia following exposure to $100 \mu \mathrm{M} \mathrm{MnCl}$, with significant suppression observed for Nos2, Il6, Ccl5, and Ccl2 (Fig. 3a). Exposure to $100 \mu \mathrm{M}$ $\mathrm{MnCl}_{2}$ in pure astrocytes resulted in significant increases in mRNA for most genes comparable to mixed glia (Fig. 3b), although Nos2, Il6, Ccl5, and $C c l 2$ in pure astrocytes had a relatively larger fold-change in mRNA levels compared to mixed glia (Fig. 3b). Bay-11 decreased expression of Nos2, $\mathrm{Ccl} 5$, and $\mathrm{Ccl} 2$ in pure astrocytes (Fig. $3 \mathrm{~b}$ ) but was less effective in decreasing expression of $C 3, I l 6, I l 1 \beta, C c r 2$, and Tnfo than in mixed glia.

\section{Pharmacologic inhibition of NF-KB in glia is neuroprotective}

To determine how glial-derived factors modulate neuronal viability following exposure to $\mathrm{MnCl} 2$, we examined the effect of Bay-11 treatment in glia on neuronal viability following incubation with GCM or ACM (Fig. 4). Pretreatment of mixed glia cultures with Bay-11 protected against Mn-induced loss of neuronal viability following incubation with GCM from Mn-treated glia, 105.2\% viable compared to GCM-saline (Fig. 4a), whereas pre-treatment of mixed glia with vehicle control (DMSO) showed no protective effect and caused neuronal viability to decrease by $\sim 23 \%$ compared to GCM-saline. There was a trend toward decreasing neuronal viability following incubation with ACM from Mn-treated astrocyte cultures that was reversed in cells treated with Bay-11, which had a relative viability of $106.3 \%$ compared to ACM-saline. DMSO co-treatment with ACM from Mn-treated astrocyte cultures showed no 


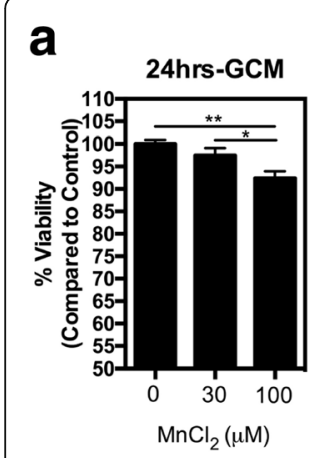

C
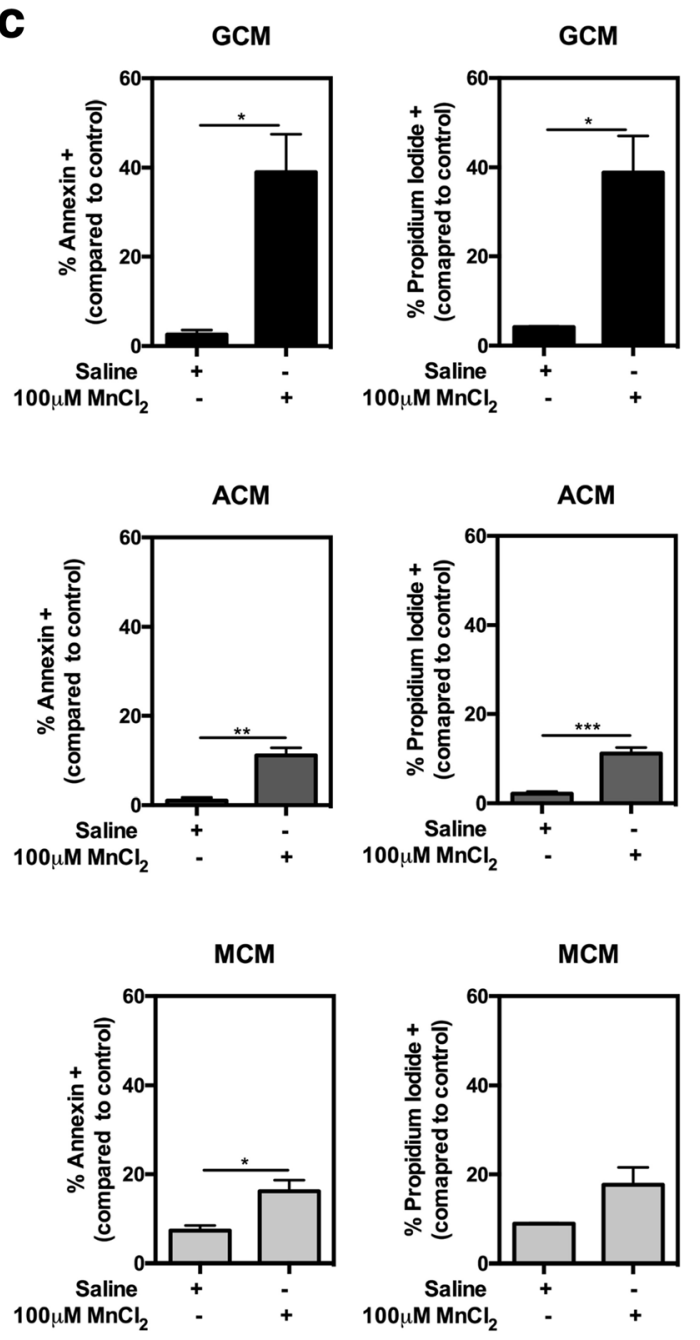
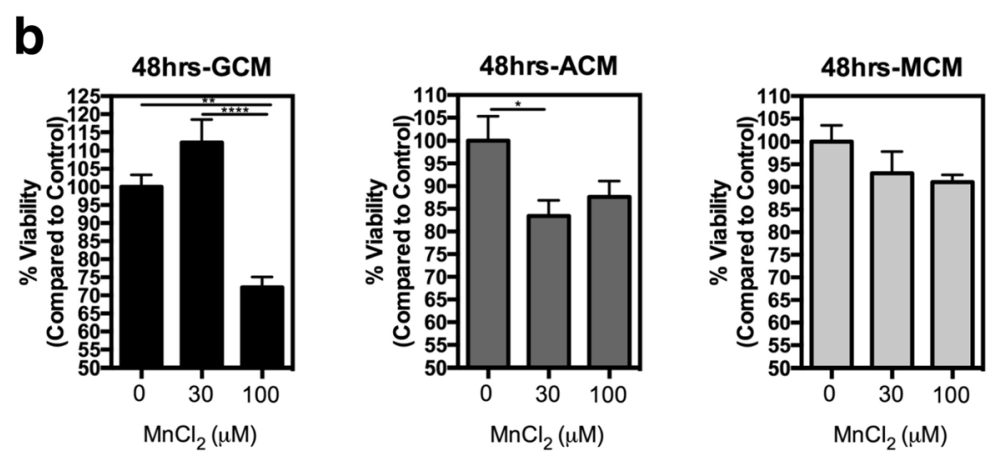

d
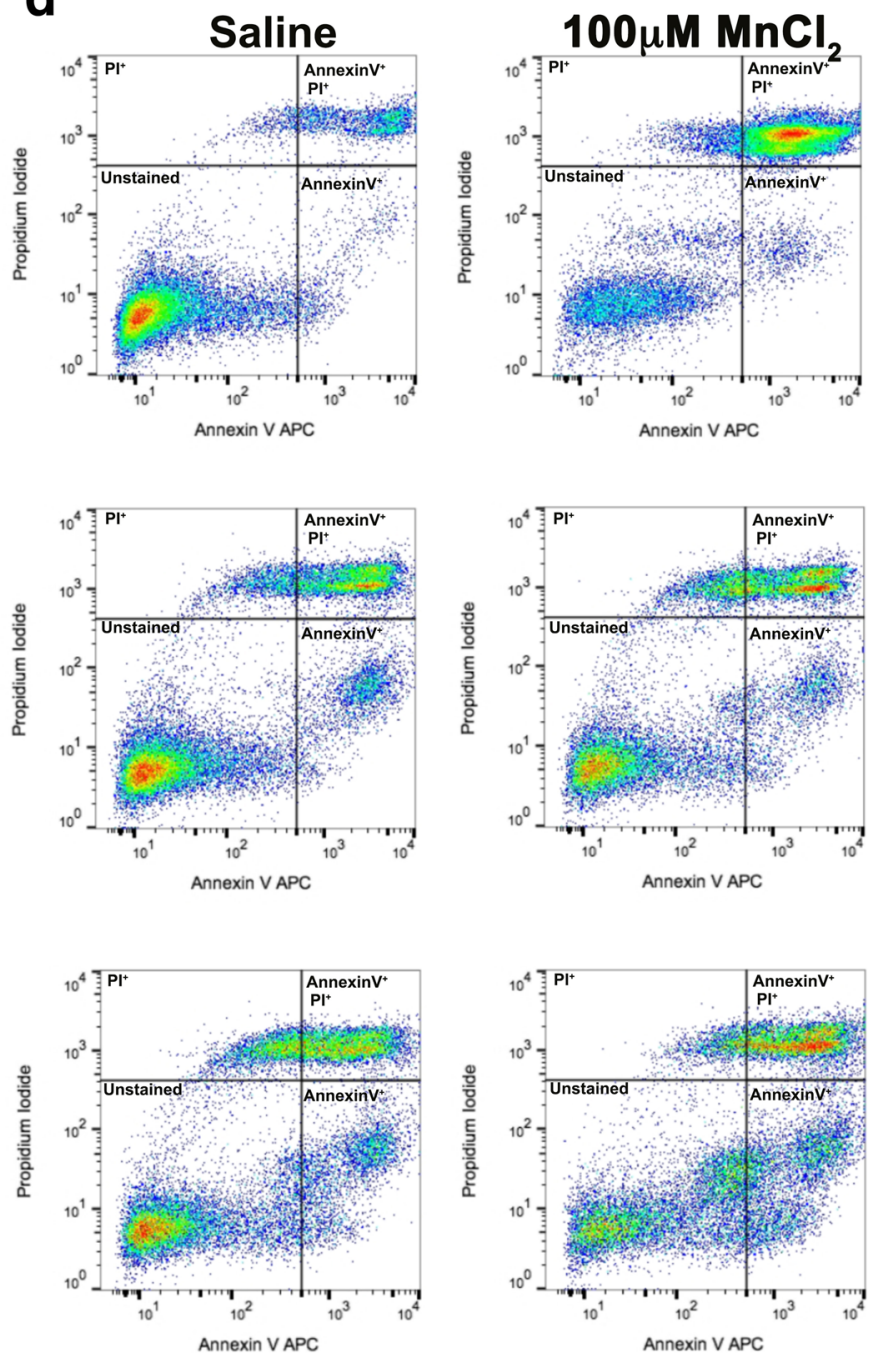

Fig. 2 Conditioned media from Mn-treated glial cultures induces cell death in N2A neuronal cells. a N2A cells exposed to Mn-exposed GCM for 24 or $48 \mathrm{~h}$ showed a dose-dependent decrease in viability at $100 \mu \mathrm{M} \mathrm{MnCl}_{2}$, more so at 48 h. b 48-h Mn-treated GCM caused a greater decrease in neuronal viability compared to either ACM or MCM. c, d (top) Flow cytometry analysis demonstrated that 48-h exposure to $100 \mu^{M} \mathrm{MnCl}_{2}{ }^{-}$ GCM increased apoptosis in N2A cells to a greater extent than ACM (c, $\mathbf{d}$ middle) or (c MCM, d bottom), based on the number of Annexin $\mathrm{V}+$ and Propidium iodide+ cells. One-way ANOVA analyses performed for experiments comparing three or more treatment groups and $t$ test in those comparing two treatment groups. Data depicted as \pm S.E.M. ${ }^{*} P<0.05$; ${ }^{* *} P<0.01 ;{ }^{* * *} P<0.001$; ${ }^{* * *} P<0.0001$ ( $n \geq 4$ per treatment group; across $\geq 3$ independent experiments) 
a Mixed Glia

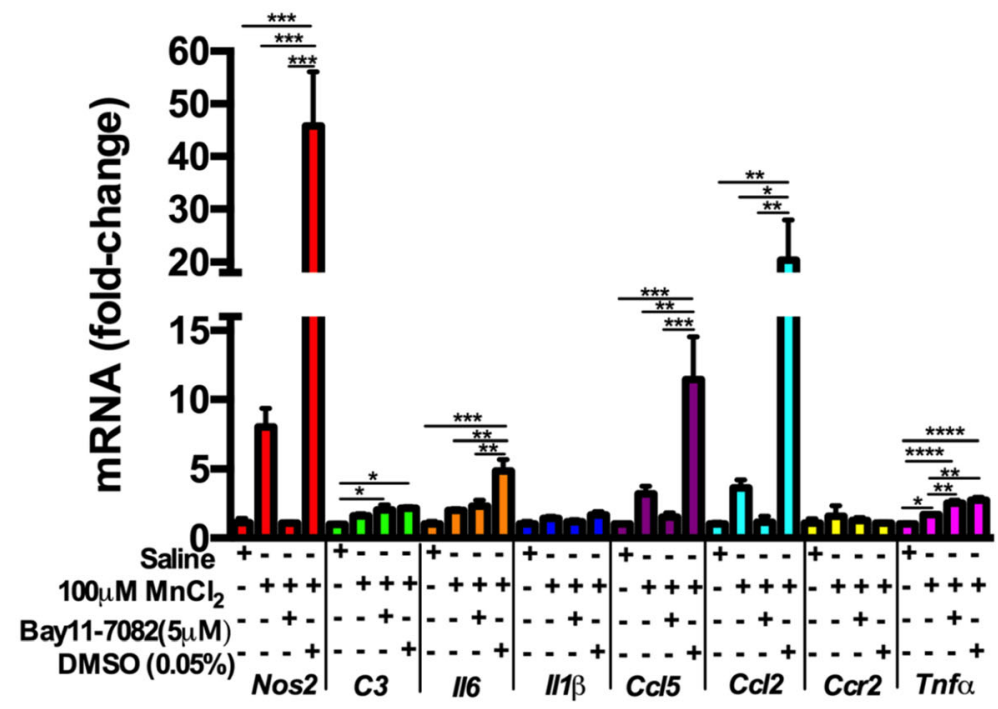

b

Astrocytes

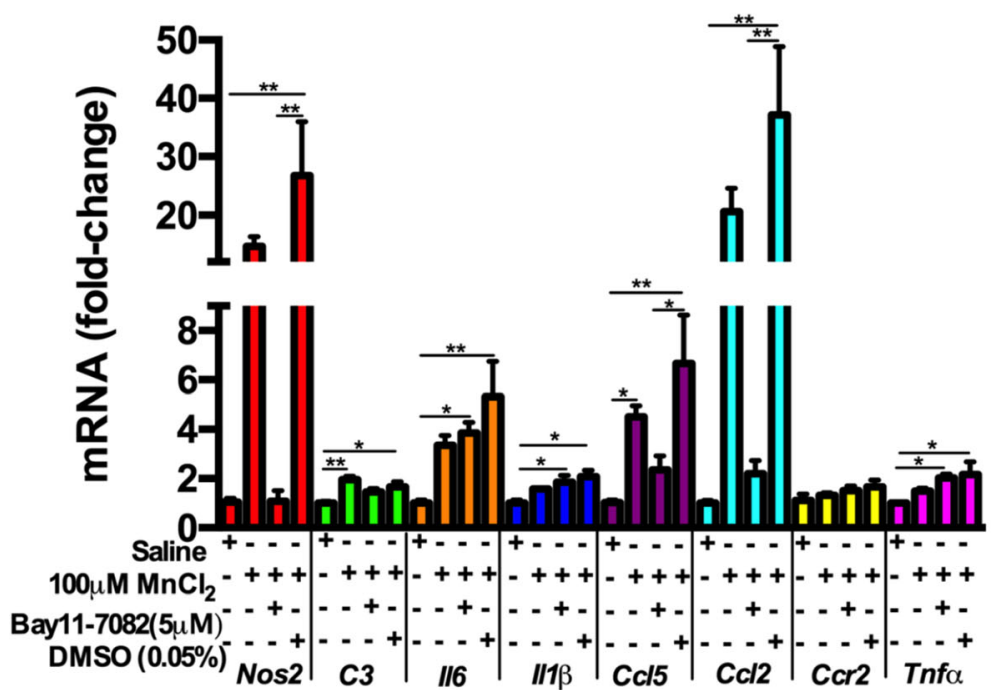

Fig. 3 Pharmacologic inhibition of NF-kB decreases inflammatory gene expression upon exposure to $100 \mu \mathrm{M} \mathrm{MnCl}$. a $1 \mathrm{~h}$ pretreatment with the NF-KB inhibitor, Bay 11-7082 (Bay-11) [(E)- 3-(4-methylphenyl) sulfonylprop-2-enenitrile], suppressed expression of inflammatory genes in mixed glia following exposure to $100 \mu \mathrm{M} \mathrm{MnCl}_{2}$. b MnCl 2 exposure in pure astrocytes was less than in mixed glia, as were the inhibitory effects of Bay11, while the DMSO-vehicle control did not suppress inflammatory gene expression in either cell type. One-way ANOVA analyses performed. Data depicted as \pm S.E.M. ${ }^{*} P<0.05 ;{ }^{* *} P<0.01 ;{ }^{* *} P<0.001 ;{ }^{* * *} P<0.0001(n \geq 4$ per treatment group; across $\geq 3$ independent experiments)

neuroprotective effect (Fig. 4b). To identify direct effects of $\mathrm{Mn}$ on neurons, N2A cells were incubated for $48 \mathrm{~h}$ with $\mathrm{MnCl}_{2}(1-1000 \mu \mathrm{M})$ and examined for viability. Treatment with increasing doses of $\mathrm{MnCl}_{2}$ resulted in loss of neuronal viability, with an $\mathrm{LD}_{50}$ value of $29.80 \pm 1.5 \mu \mathrm{M}$ (Fig. 4c). Analysis of N2A cells by flow cytometry following direct treatment with $\mathrm{MnCl}_{2}$ demonstrated increased numbers of apoptotic (+Annexin V) cells and a modest increase in dead
(+Propidium Iodide (PI)) neurons (Fig. 4d, e). The magnitude of neuronal apoptosis following direct treatment with $\mathrm{MnCl}_{2}$ was markedly less than that induced by GCM or ACM. Flow cytometric analysis also demonstrated that Bay-11 treatment in mixed glia or pure astrocytes exposed to $100 \mu \mathrm{M} \mathrm{MnCl}_{2}$ was neuroprotective in both GCM (Fig. 4f, h) and ACM (Fig. 4g, i) treatment groups, respectively, based upon fluorescence intensity of Annexin V and PI. 


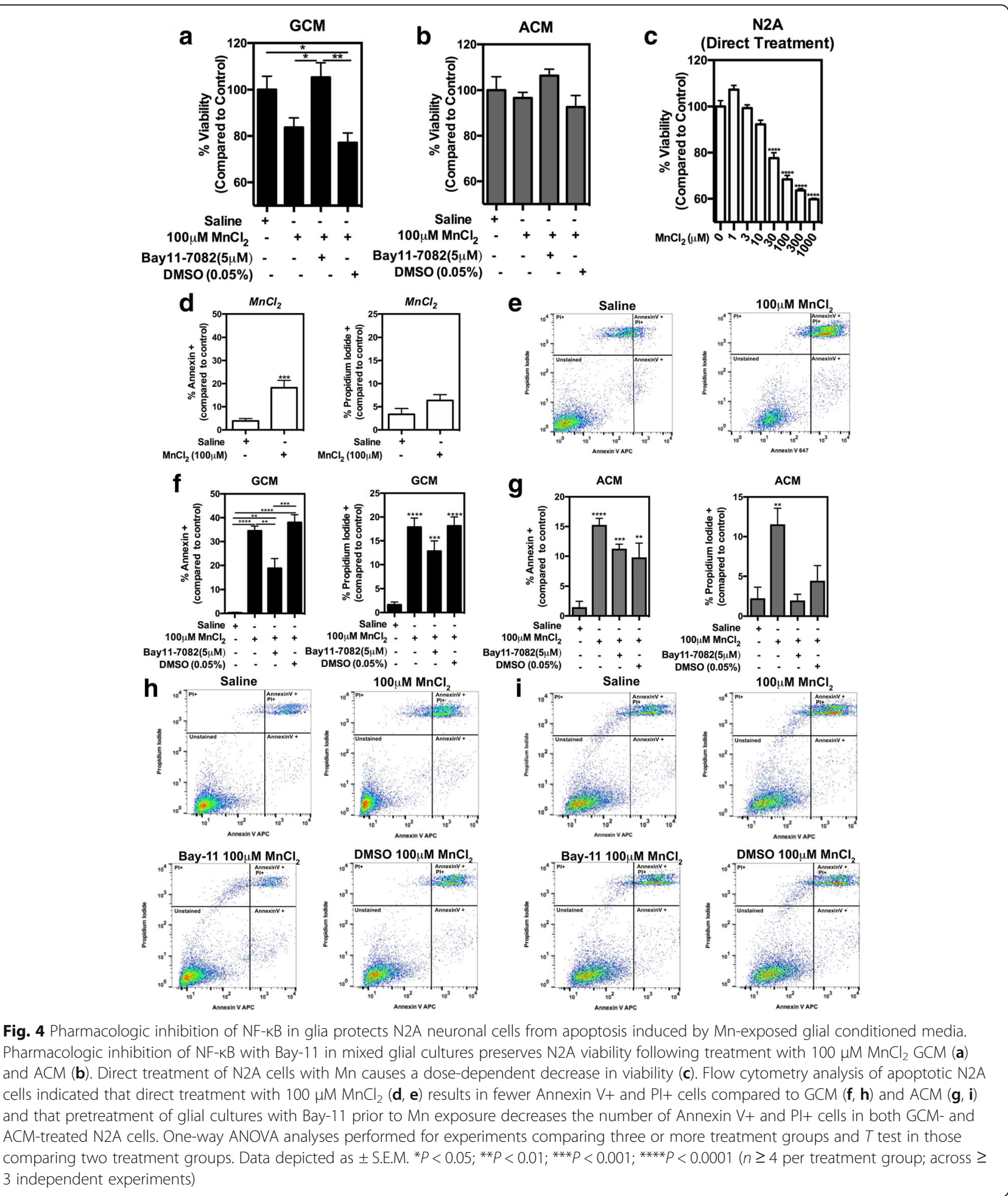

Gene deletion of IKK (NF-KB) in astrocytes decreases inflammatory gene expression

To determine the function of NF-kB in astrocytemicroglia inflammatory signaling, we treated mixed glial cultures containing IKK2 knockout (KO) astrocytes and wild-type microglia with $100 \mu \mathrm{M} \mathrm{MnCl}$ for $8 \mathrm{~h}$ and assessed mRNA expression of inflammatory genes (Fig. 5). These data demonstrate that astrocyte-specific knockout of IKK2 drastically decreases inflammatory gene expression for all genes including Nos2, C3, Il6, Il1 $\beta, C c l 5, C c l 2$, Ccr2, and Tnfo, compared to mixed glia containing both littermate control wild-type astrocytes and microglia 


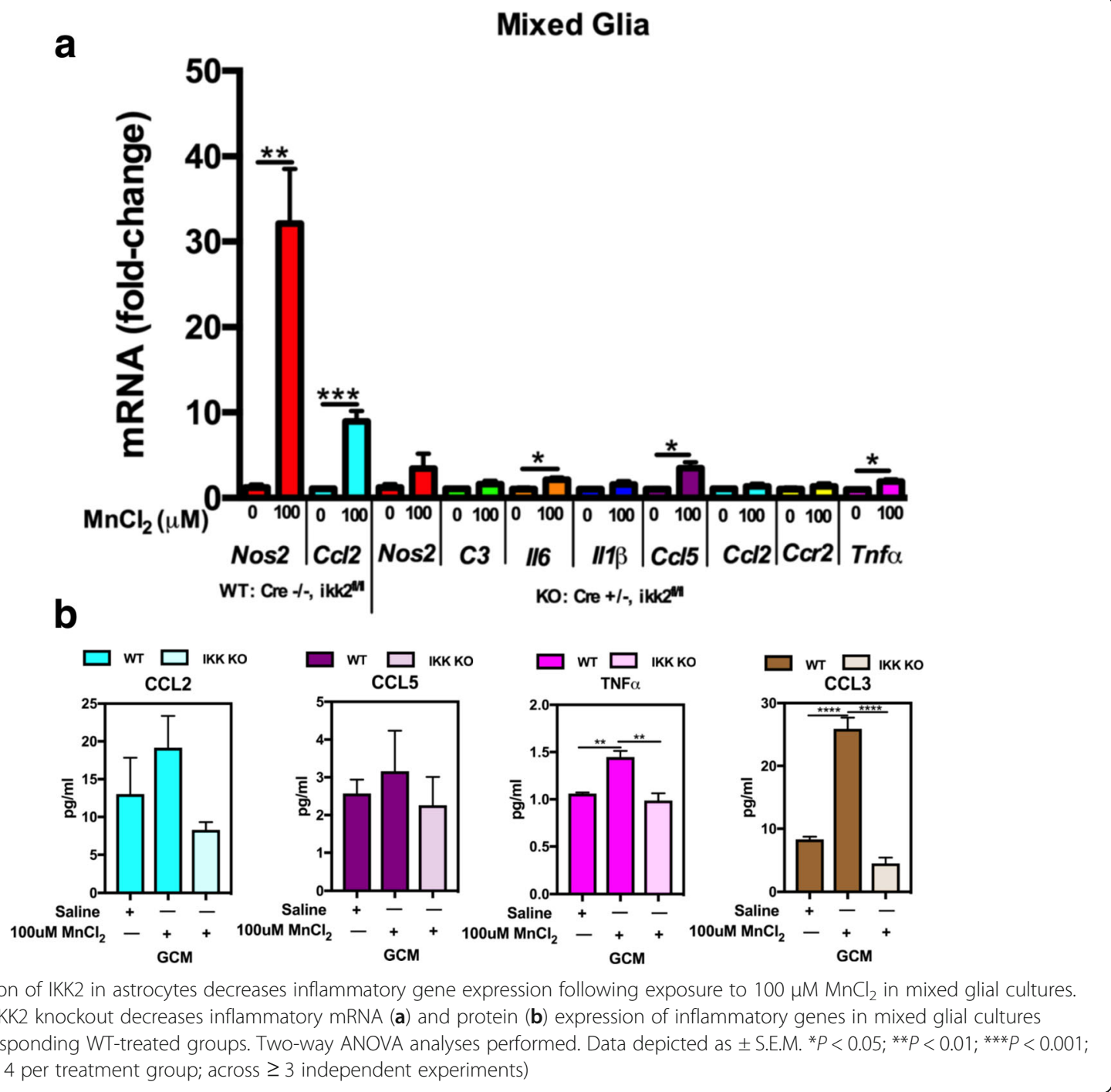

(Fig. 5a). Additionally, the resultant GCM from these experiments was examined by ELISA for protein levels of some of the genes targeted in mRNA studies, which also demonstrates that astrocyte-specific IKK knockout decreases protein levels of several NF-кB-regulated inflammatory genes (Fig. 5b).

\section{Genetic inhibition of astrocyte-specific NF-KB in glia is neuroprotective}

To determine the role of $\mathrm{IKK} 2 / \mathrm{NF}-\mathrm{kB}$ in astrocytes in glial-mediated neuronal cell death during exposure to $\mathrm{Mn}$, we assessed N2A cell viability after exposure to GCM from mixed glia containing IKK2 WT or KO astrocytes treated with saline or $100 \mu \mathrm{M} \mathrm{MnCl} 2$ (Fig. 6). These data indicate that GCM from mixed glia containing IKK KO astrocytes almost completely preserved N2A cell viability after exposure to $100 \mu \mathrm{M} \mathrm{MnCl}$, with only $\sim 5 \%$ reduction in viability (Fig. 6a white bars) compared to exposure to GCM from mixed glia containing WT astrocytes, in which there was $20 \%$ reduction in N2A cell viability (Fig. 6a black bars). Flow cytometric analysis of N2A cells exposed to IKK KO astrocyte GCM demonstrated a significant decrease in apoptotic (4.47\% Annexin V+) (Fig. 6b white bars) and dead (4.62\% PI +) (Fig. 6c white bars) N2A cells compared to wild-type GCM-100 $\mu \mathrm{M} \mathrm{MnCl}_{2}$ (12.33\% Annexin V+) and (9.14\% PI+) (Fig. 6b, c black bars).

Genetic inhibition of IKK (NF-KB) in astrocytes protects primary neurons from $\mathrm{Mn}$-dependent inflammatory injury Additionally, we wanted to assess the effects of GCM from mixed glia containing IKK KO astrocytes and wild-type microglia on the viability of primary neurons. We therefore exposed primary neurons to GCM from Mn-treated mixed glia containing either WT astrocytes + WT microglia (WT) or IKK2 KO astrocytes + WT microglia (IKK KO)) for $48 \mathrm{~h}$, similar to treatments done in N2A cells. Primary neurons 


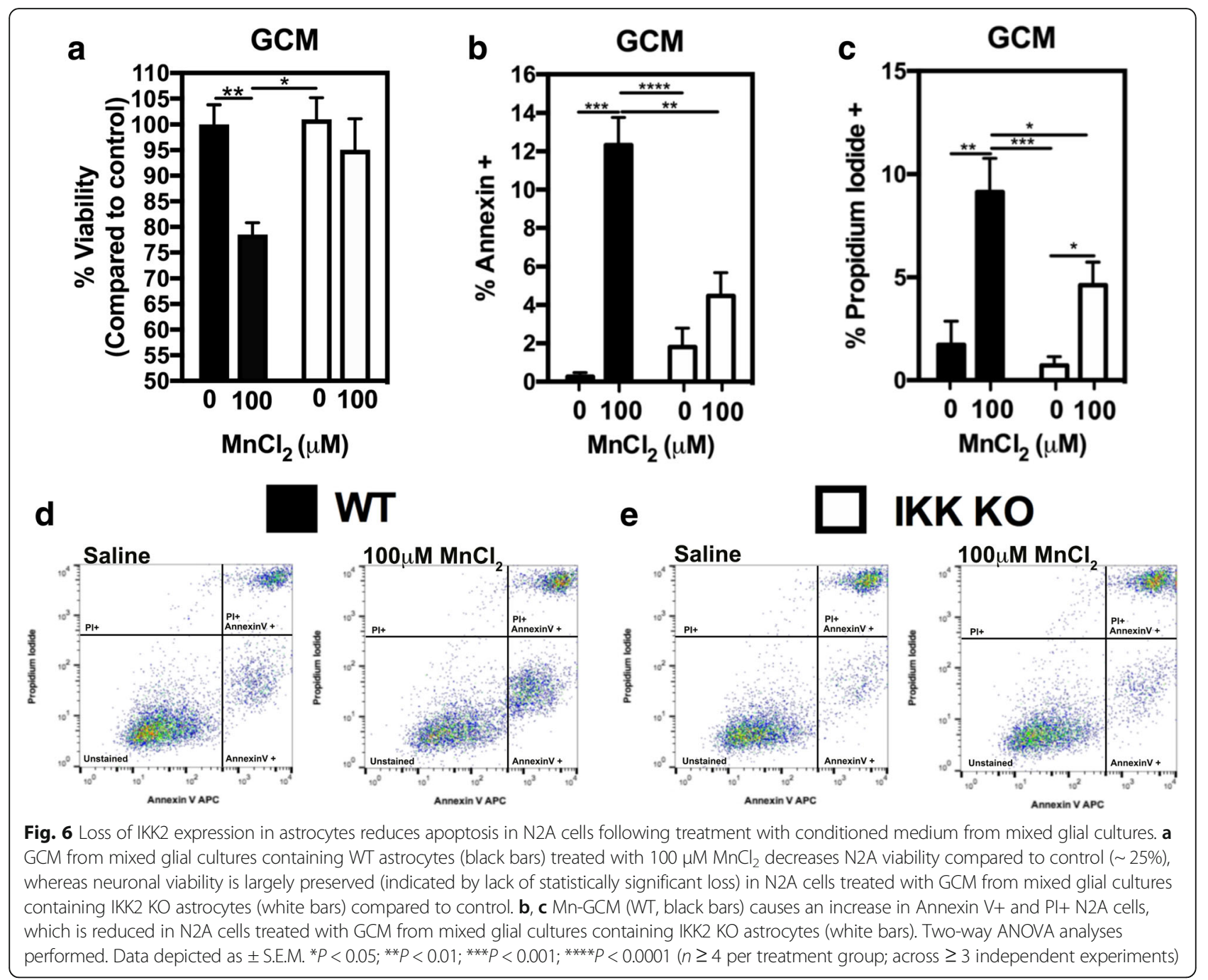

exposed to WT GCM showed a significant $\sim 5$-fold increase in positive for Annexin $\mathrm{V}+$ cells compared to those exposed to IKK2 KO GCM (Fig. 7a). Representative images demonstrating loss of neuronal morphology and increased Annexin V staining are depicted in cells exposed to WT GCM compared to IKK2 KO GCM and are depicted in Fig. 7b. Similarly, increases in caspase 3/7 activation (Fig. 7c, d) and in the number of PI+ cells (Fig. 7e, f) were detected in primary neurons exposed to WT but not IKK2 KO GCM.

Knockdown of CCL2 in astrocytes reduces neuronal cell death from $\mathrm{Mn}$-exposed mixed glial cultures

Because expression of the astrocyte-specific chemokines, C3 and CCL2, is regulated by NF- $\mathrm{B}$ and increased upon Mn exposure in mixed glia, we examined whether C3 or CCL2 gene expression in astrocytes modulates $\mathrm{Mn}$-induced inflammatory responses in mixed glia (Fig. 8). We therefore used siRNA to knock down both C3 ( 90\% KD; Fig. 8e) and CCL2 ( 95\% KD; Fig. 8a, b) separately in mixed glial cultures prior to Mn exposure (Fig. 8a). Rather than causing a decrease in expression of other inflammatory genes, knockdown of C3 (Fig. 8e) and CCL2 (Fig. 8a) resulted in either no change or greater inflammatory gene induction compared to scramble control siRNA following Mn treatment. N2A viability assays revealed that GCM from CCL2 KD mixed glia resulted in preservation of neuronal viability following treatment with Mn-exposed GCM (Fig. 8c), whereas C3 knockdown had no effect on Mn-induced loss of neuronal cell viability (Fig. 8f). Additionally, ELISA assays demonstrated increased CCL2 in both mixed glial populations and in pure astrocyte populations following exposure to $\mathrm{Mn}$ (Fig 8d, left two panels), as well as levels of CCL2 that were below the limit of detection once mixed glia and pure astrocytes were exposed to $\mathrm{Mn}$ in the presence of Bay-11 (Fig. 8d, two right panels).

\section{Discussion}

Mn-induced neurotoxicity in humans and in animal models is accompanied by reactive gliosis and inflammation that is damaging to surrounding neurons, although 

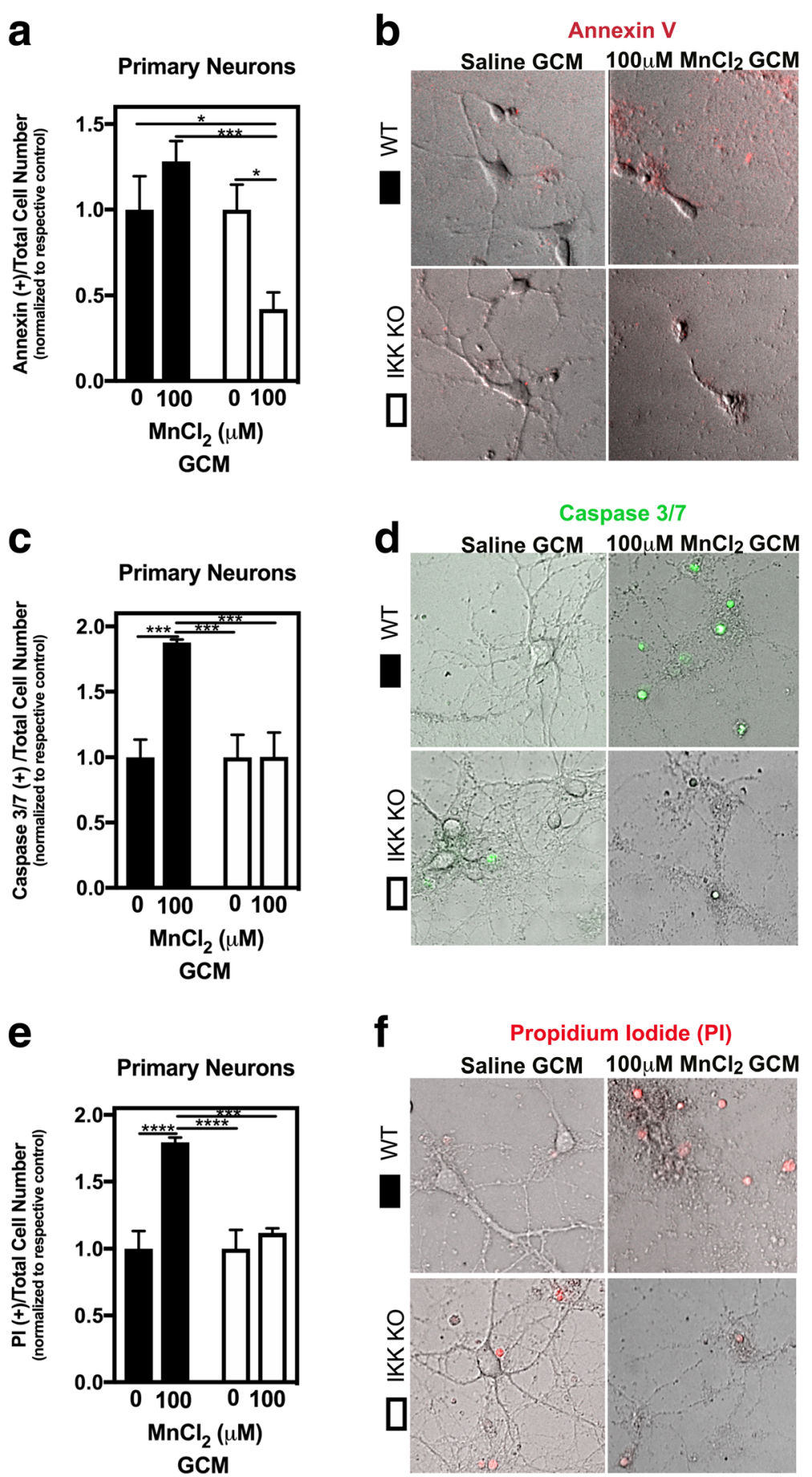

Fig. 7 Mixed glial cultures containing IKK2 knockout astrocytes fail to induce apoptosis in primary cortical neurons following exposure to $\mathrm{MnCl}_{2}$. The number of apoptotic neurons is statistically decreased in response to Mn-treated IKK2 KO GCM compared to WT GCM for Annexin V+ cells $(\mathbf{a}, \mathbf{b})$ and caspase $3 / 7+$ cells $(\mathbf{c}, \mathbf{d})$. Necrotic neurons (PI+; e, f) are similarly, statistically decreased in neurons treated with IKK2 KO GCM compared to WT GCM. Two-way ANOVA analyses performed. Data depicted as \pm S.E.M. ${ }^{*} P<0.05 ;{ }^{*} P<0.01 ;{ }^{* *} P<0.001 ;{ }^{* * *} P<0.0001(100-200$ cells per group from four biological replicates across $\geq 3$ independent experiments)

mechanisms regulating this neuroinflammatory phenotype remain poorly understood. Multiple studies have reported that microglia and astrocytes respond to $\mathrm{Mn}$ exposure with elevated levels of NF-kB-regulated inflammatory cytokines and other inflammatory mediators [11, 17, 25]. Furthermore, other studies have evaluated glial responses 


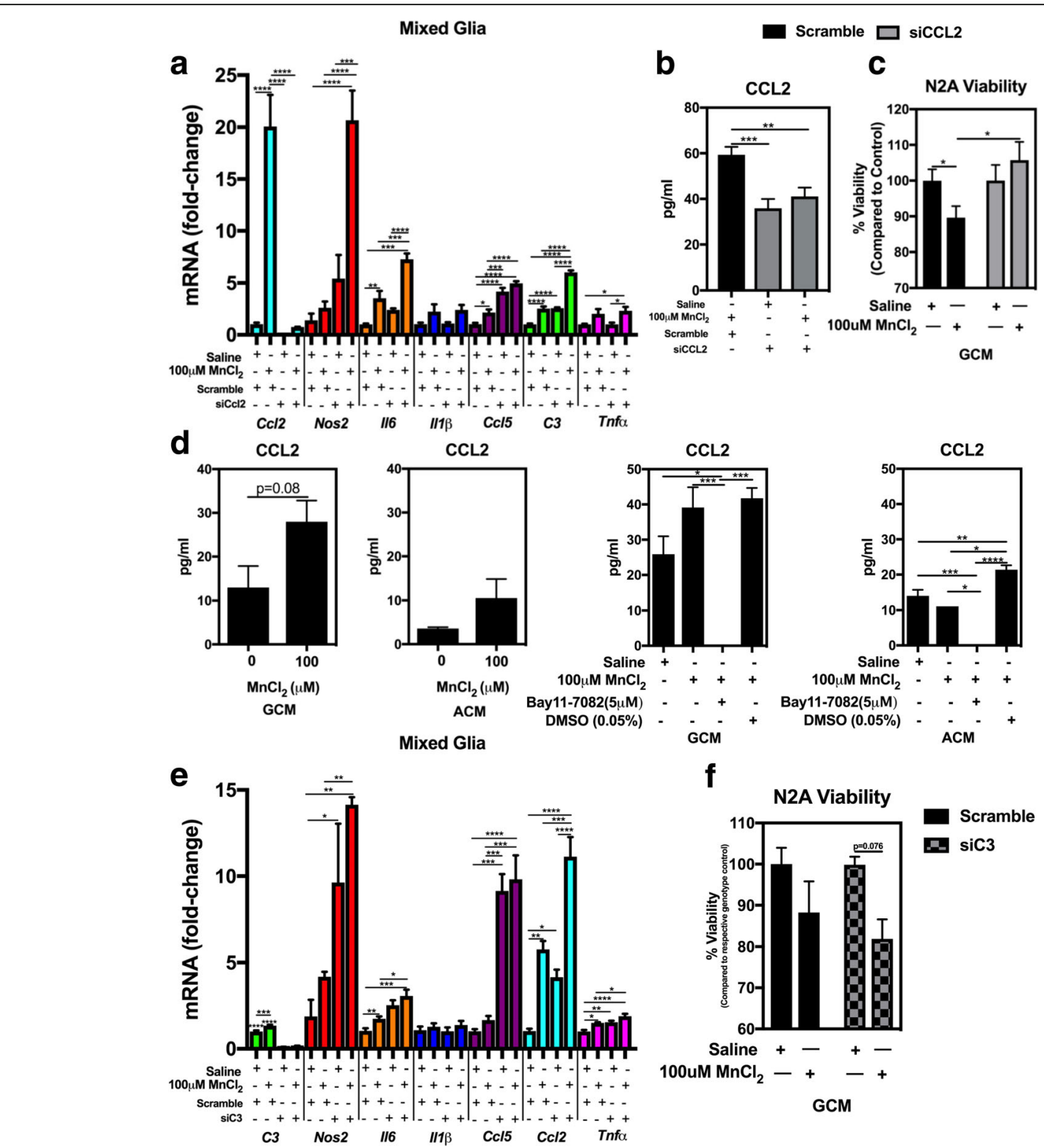

Fig. 8 Selective knockdown of the astrocyte-specific chemokine, CCl2, with siRNA in mixed glia does not inhibit Mn-induced inflammatory gene expression but prevents neuronal cell death. a C 12 KD does not inhibit mRNA expression of inflammatory genes in Mn-exposed mixed glia compared to mixed glia treated with $\mathrm{Mn}$ in the presence of control siRNA. b CCL2 protein levels in GCM are reduced in CCl2 KD mixed glial cultures. c Viability of N2A cells is preserved following treatment with Mn-GCM from CCI2 KD mixed glia compared to those treated with control siRNA Mn-GCM. d (left two panels) CCL2 is released into medium in both mixed glia (GCM) and pure astrocytes (ACM) following treatment with $\mathrm{MnCl}_{2}$. $\mathbf{d}$ (right two panels) Pharmacologic inhibition of NF-KB with Bay-11 in both mixed glia and pure astrocyte cultures inhibits release of CCL2, whereas CCL2 levels are statistically increased compared to control in both Mn-GCM and Mn-ACM treated with vehicle control (DMSO). e C3 KD does not inhibit mRNA expression of inflammatory genes in Mn-exposed mixed glia compared to mixed glia treated with Mn in the presence of control siRNA. f N2A viability is decreased in cells exposed to C3 KD Mn-GCM compared to those treated with siRNA control Mn-GCM. One-way ANOVA analyses performed for experiments comparing three or more treatment groups and $t$ test in those comparing two treatment groups. Data depicted as \pm S.E.M. ${ }^{*} P<0.05$; ${ }^{* *} P<0.01 ;{ }^{* * *} P<0.001 ;{ }^{* * *} P<0.0001$ ( $\geq 4$ per treatment group; across $\geq 3$ independent experiments)

as a result of Mn-induced neuronal cell death [13]; however, research assessing the role that glial-glial and glial-neuronal communication plays in neurodegeneration in a model of manganism is lacking.
To identify glial-derived factors involved in neuronal injury as a result of Mn exposure, we first assessed Mn-induced inflammatory gene expression in three glial populations. We treated astrocytes and microglia, either together or 
separately, for $8 \mathrm{~h}$ with 0,30 , or $100 \mu \mathrm{M} \mathrm{MnCl}_{2}$. Overall, in mixed glial cell cultures, there was a dose-dependent increase in several NF-kB-regulated inflammatory genes including Nos2, Il6, and $I l 1 \beta$ (Fig. 1a) that was much greater than in pure astrocytes (Fig. 1b) or pure microglia alone (Fig. 1c), suggesting that microglia-astrocyte communication amplifies the inflammatory response to $\mathrm{Mn}$. Interestingly, the complement component $C 3$, which is uniquely expressed by activated astrocytes in the CNS and correlates closely with a neurotoxic inflammatory phenotype (A1 astrocytes) [26], was more highly induced in mixed glia $(\sim 4$-fold more in $100 \mu \mathrm{M}$ compared to $0 \mu \mathrm{M}$ ) than in pure astrocytes (only 2-fold increase), whereas pure microglia showed a dose-dependent decrease upon Mn-exposure, consistent with findings that show $C 3$ is not significantly expressed by microglia [26]. This demonstrates that $C 3$ is induced in astrocytes following $\mathrm{Mn}$ exposure and also that microglia potentiate expression of inflammatory gene expression in astrocytes, similar to in vivo studies reporting that release of the inflammatory cytokines C1q, IL1a, and TNF by microglia induces reactive astrocytosis in vivo [26]. Additionally, the chemokine, $\mathrm{Ccl} 2$, was induced following $\mathrm{Mn}$ exposure in mixed glia and in pure astrocytes but not in pure microglial cultures, consistent with studies demonstrating that $\mathrm{Ccl} 2$ is astrocyte-derived and increases microglial activation and neuroinflammation [27, 28]. This suggests that cell-cell communication between microglia and astrocytes promotes an increase in astrocytic-specific inflammatory gene expression compared to astrocytes cultured in the absence of microglia, possibly through increased astrocyte expression of $\mathrm{Ccl}$. Other studies have also implicated CCL2-CCR2 signaling in astrocyte-mediated microglial activation in central nervous system (CNS) inflammation [27, 28], suggesting that the increase in both $\mathrm{Ccl} 2$ and $\mathrm{Ccr} 2$ in mixed glia is what contributes to an increased inflammatory gene response due to $\mathrm{Mn}$ treatment.

To determine whether glia release neurotoxic factors as a result of $\mathrm{Mn}$ exposure, we incubated N2A cells with conditioned media from cultures of mixed glia (GCM), astrocytes $(\mathrm{ACM})$, or microglia $(\mathrm{MCM})$ and found that $48 \mathrm{~h}$ of exposure to $100 \mu \mathrm{M} \mathrm{Mn-GCM}$ caused a greater decrease in neuronal viability compared to either ACM or MCM. Although purified astrocytes and microglia elicited some loss of neuronal viability in response to $\mathrm{Mn}$, this was magnified with both cell types present, consistent with other studies demonstrating that $\mathrm{Mn}$ increases production in inflammatory cytokines and chemokines [5, 15, 17]. These data also suggest that cell-cell signaling between astrocytes and microglia amplifies the overall neuroinflammatory response to $\mathrm{Mn}$, similar to recent studies from our lab demonstrating that microglia-derived inflammatory cytokines were greater in the presence of astrocytes than in pure microglial cultures [6]. Flow cytometric analysis also indicated that $\mathrm{N} 2 \mathrm{~A}$ cell death was enhanced by exposure to Mn-GCM, as shown by staining for Annexin $\mathrm{V}$ and Propidium Iodide for apoptotic and necrotic cells, respectively (Fig. 2c, d). This suggests that mixed populations of astrocytes and microglia produce more damaging levels of inflammatory mediators than either cell type alone, likely due to glial-glial communication that intensifies a reactive phenotype.

Because many inflammatory cytokines and chemokines associated with innate immune response in Mn-exposed glial cells are regulated by NF-kB $[16,25$, $29]$, we tested the function of this signaling pathway in regulating astrocyte cross-communication with microglia. Treating purified astrocytes or mixed glia with the NF- $\mathrm{kB} / \mathrm{IKK} 2$ inhibitor, Bay 11-7082, prior to treatment with $100 \mu \mathrm{M}$ Mn resulted in significant reductions in glial activation, based on expression of inflammatory genes. The inflammatory genes upregulated (Nos2, C3, Il6, Il1 $\beta, C c l 5, C c l 2, C c r 2$, and Tnfo) by Mn exposure were significantly decreased in both mixed glia and pure astrocytes, suggesting that $\mathrm{Mn}$-induced inflammatory gene expression in mixed glia and astrocytes requires activation of NF- $\mathrm{kB}$.

The functional effect of Bay-11 in Mn-treated glia was determined in neuronal viability studies using GCM or ACM derived from Bay-11-pretreated glial cells (Fig. 4). Bay-11 pretreatment was significantly neuroprotective (Fig. 4a) in GCM-treated N2A cells, whereas ACM showed a similar but less potent trend (Fig. 4b). Direct treatment of N2A cells with Mn demonstrated that the LD50 was $30 \mu \mathrm{M}$ and that Mn also directly increased the number of apoptotic (Annexin V-positive) and necrotic (PI-positive) neuronal cells, although to a lesser extent than Mn-treated GCM or ACM (Fig. 4c-e). This finding supports that glial-derived factors contribute to N2A cell death. We previously reported that glial uptake of $\mathrm{Mn}$ is $\sim 70 \%$, leaving behind $\sim 30 \%$ of $\mathrm{Mn}$ in the conditioned medium [6]; thus, uptake of $70 \%$ of $100 \mu \mathrm{M}$ Mn treatment would result in $\sim 30 \mu \mathrm{M}$ in the resultant conditioned media, which caused greater cell death than direct treatment of N2A cells with $30 \mu \mathrm{M} \mathrm{Mn}$. This finding suggests that N2A cell death from conditioned media exposure is not solely due to residual $\mathrm{Mn}$ in the media but is due in part to glial-released inflammatory factors, most likely regulated by NF-kB. This is further supported by the flow cytometric analysis of GCM and ACM from Bay-11 experiments in which there is increased neuroprotection as demonstrated by the significant decrease in apoptotic (Annexin V) and necrotic (PI) positive staining in N2A cells exposed to Bay-ll-pretreated GCM (Fig. 4f, h) or ACM (Fig. 4g, i). Taken together, these findings support the involvement of NF- $\mathrm{kB}$ activation in glial cells in the neurotoxicity of $\mathrm{Mn}$ by demonstrating that pharmacologic inhibition of NF- $\mathrm{kB}$ in glia is anti-inflammatory and neuroprotective. 
To more precisely establish the involvement of NF- $\mathrm{kB}$ in Mn-induced glial inflammation and neuronal cell death, we isolated primary mixed glia from astrocyte-specific IKK knockout (KO) mice and exposed the mixed glia (containing IKK KO astrocytes and wild-type microglia) to $100 \mu \mathrm{M} \mathrm{Mn}$ for $8 \mathrm{~h}$. We showed that there was a significant decrease in inflammatory gene expression based on levels of both mRNA and protein for multiple NF- $\mathrm{kB}$-regulated inflammatory genes (Fig. 5), suggesting not only that NF- $\mathrm{kB}$ is directly involved in Mn-induced inflammatory gene expression, but also that genetically inhibiting NF- $\mathrm{KB}$ in astrocytes in a mixed glial culture mitigates overall expression of inflammatory genes in both astrocytes as well as microglia following exposure to $\mathrm{Mn}$.

Exposing N2A cells to GCM from astrocyte-specific IKK2 knockout mixed glial cultures resulted in almost complete neuroprotection in GCM-treated N2A cells (Fig. 6a), with significantly fewer apoptotic (Annexin V) and necrotic (PI) positive staining (Fig. 6b, c). Additionally, incubation of primary cortical neurons with GCM from astrocyte-specific IKK2 knockout mixed glial cultures resulted in similar neuroprotection in live cell imaging experiments (Fig. 7), with decreased apoptotic (Annexin V), necrotic (PI), and active caspase 3/7-positive cells. This suggests that IKK2-dependent activation of NF- $\mathrm{kB}$ in astrocytes in response to $\mathrm{Mn}$ is critical for inflammatory injury to neurons, likely through the release of numerous neurotoxic inflammatory mediators that both directly injure neurons and amplify the inflammatory response of microglia.

To begin to identify astrocyte-derived factors that could result in amplification of glial inflammatory signaling and subsequent neuronal injury, we knocked down (KD) two NF-kB-mediated genes specific to astrocytes, $\mathrm{C} 3$ and $\mathrm{Ccl} 2$ $[26,27]$, and determined the effect on inflammatory gene expression and neuronal injury (Fig. 8). Knockdown of either C3 or Ccl2 did not diminish inflammatory gene expression in mixed glial cultures, indicating that these factors are not directly involved in glial cross-communication leading to amplification of inflammatory signaling. This is not surprising, given previous studies from our laboratory identifying TNF as a key regulator of glial reactivity in response to $\mathrm{Mn}$ [6]. However, TNF-dependent activation of NF-kB and subsequent production of $\mathrm{C} 3$ or CCL2 could still be directly toxic to associated neurons following exposure to $\mathrm{Mn}$. To test this hypothesis, we incubated N2A cells with GCM from mixed glial cultures in which RNAi knocked down astrocytic expression of $\mathrm{C} 3$ or $\mathrm{Ccl} 2$. Treatment of N2A cells with GCM from C3 KD mixed glial cultures did not prevent Mn-dependent injury, whereas CCL2 KD GCM significantly decreased N2A cell death (Fig. 8c), demonstrating that CCL2 expression in astrocytes is necessary for glial-mediated neuronal cell death in response to $\mathrm{Mn}$ treatment. These data not only suggest that NF-kB activation in astrocytes is specifically involved in $\mathrm{Mn}$-induced neuronal injury but also that astrocyte-derived CCL2 is a key contributor to neuronal cell death in a model of Mn neurotoxicity. The factor(s) regulated by CCL2 in microglia and astrocytes that cause direct injury to neurons following $\mathrm{Mn}$ exposure remain to be further elucidated.

\section{Conclusions}

The mechanisms underlying neuronal death from exposure to $\mathrm{Mn}$ are not well understood but may be mediated by glial inflammation. Expression of neurotoxic inflammatory genes in glia is highly regulated through the NF- $\mathrm{kB}$ pathway, but the specific factors modulating neurotoxic glial-glial and glial-neuronal signaling by $\mathrm{Mn}$ are not well understood. The present data build on recently reported studies from our laboratory indicating that microglia amplify astrocyte activation during Mn exposure [6] and demonstrate that NF- $\mathrm{kB}$ in astrocytes stimulates the production of inflammatory cytokines and chemokines that cause neuronal cell death. Inhibition of NF-KB in astrocytes resulted in decreased inflammatory gene activation in mixed glia and increased neuroprotection, thus providing evidence that glial-glial and glial-neuronal communication through astrocyte-specific NF- $\mathrm{kB}$ is critical to mediating neurotoxic inflammatory signaling in response to Mn. Moreover, NF-кB-dependent expression of CCL2 in astrocytes appears to be critical to the inflammatory response to Mn exposure and to neuronal injury. Collectively, these data demonstrate that astrocyte-microglial signaling amplifies neuroinflammatory injury from $\mathrm{Mn}$ and suggests several inflammatory mediators regulated by $\mathrm{NF}-\mathrm{kB}$ in astrocytes that likely influence the overall level of glial reactivity during exposure to $\mathrm{Mn}$.

\section{Abbreviations}

ACM: Astrocyte-conditioned media; CCL2: C-C motif chemokine ligand 2; CCL3: CC motif chemokine ligand 3; CCL5: C-C motif chemokine ligand 5; CCR2: C-C chemokine receptor type 2; CD11b: C3: complement receptor; ELISA: Enzymelinked immunosorbent assay; GCM: Glia-conditioned media; GFAP: Glial fibrillary acidic protein; GLAST: Glutamate transporter; IBA-1: Ionized calcium binding adaptor molecule 1; IL-6: Interleukin-6; IL-1ß: Interleukin-1 beta; MCM: Microgliaconditioned media; Mn: Manganese; N2A: Neuro-2a; NF-kB: Nuclear factor kappa B; NOS2: Nitric oxide synthase 2; TNF: Tumor necrosis factor alpha

\section{Acknowledgements}

The authors acknowledge the support of Chris Allen and the flow cytometry core in the College of Veterinary Medicine and Biomedical Sciences at Colorado State University for the help with conducting and analyzing cytometry experiments.

\section{Funding}

This work was supported by NIH grants ES021656 and ES026860.

\section{Availability of data and materials}

The datasets during and/or analyzed during the current study are available from the corresponding author on reasonable request.

\section{Authors' contributions}

KAP designed and performed the experiments, excluding flow cytometry, collected, analyzed, and presented all data, and composed the majority of the written manuscript. MFA processed and ran the flow cytometry 
experimentation and analyzed all flow cytometry data with minor contribution to manuscript writing. KSK designed the transgenic mouse utilized in the current study for isolation of primary glial cultures, helped interpret some experimentation, and was a large contributor to the manuscript. RBT oversaw, helped design/interpret experimentation, and was a major contributor in the writing of the manuscript. All authors read and approved the final manuscript

\section{Authors' information}

Not applicable. Information presented on title page per the "instructions to authors."

\section{Ethics approval and consent to participate}

All procedures were performed in accordance with National Institutes of Health guidelines for the care and use of laboratory animals with approval by the Institutional Animal Care and Use Committee of Colorado State University.

\section{Consent for publication}

Not applicable

\section{Competing interests}

The authors declare that they have no competing interests.

\section{Publisher's Note}

Springer Nature remains neutral with regard to jurisdictional claims in published maps and institutional affiliations.

\section{Author details}

'Department of Environmental and Radiological Health Sciences, College of Veterinary Medicine and Biomedical Sciences, Colorado State University, 1680 Campus Delivery, Physiology Building, Room 101, Fort Collins, CO 80523-1680, USA. ²Department of Microbiology, Immunology and Pathology, College of Veterinary Medicine and Biomedical Sciences, Colorado State University, Fort Collins, CO, USA. ${ }^{3}$ Department of Biomedical Sciences, College of Veterinary Medicine and Biomedical Sciences, Colorado State University, Fort Collins, CO, USA.

Received: 13 August 2018 Accepted: 29 October 2018

\section{Published online: 21 November 2018}

\section{References}

1. Collipp PJ, Chen SY, Maitinsky S. Manganese in infant formulas and learning disability. Ann Nutr Metab. 1983;27(6):488-94.

2. Woolf A, Wright R, Amarasiriwardena C, Bellinger D. A child with chronic manganese exposure from drinking water. Environ Health Perspect. 2002; 110(6):613-6.

3. Riojas-Rodriguez H, Solis-Vivanco R, Schilmann A, Montes S, Rodriguez S, Rios C, Rodriguez-Agudelo Y. Intellectual function in Mexican children living in a mining area and environmentally exposed to manganese. Environ Health Perspect. 2010;118(10):1465-70.

4. Hua MS, Huang CC. Chronic occupational exposure to manganese and neurobehavioral function. J Clin Exp Neuropsychol. 1991;13(4):495-507.

5. Filipov NM, Dodd CA. Role of glial cells in manganese neurotoxicity. J Appl Toxicol. 2012;32(5):310-7.

6. Kirkley KS, Popichak KA, Afzali MF, Legare ME, Tjalkens RB. Microglia amplify inflammatory activation of astrocytes in manganese neurotoxicity. J Neuroinflammation. 2017;14(1):99.

7. Giordano G, Pizzurro D, VanDeMark K, Guizzetti M, Costa LG. Manganese inhibits the ability of astrocytes to promote neuronal differentiation. Toxicol Appl Pharmacol. 2009;240(2):226-35.

8. Sidoryk-Wegrzynowicz M, Aschner M. Role of astrocytes in manganese mediated neurotoxicity. BMC Pharmacol Toxicol. 2013;14:23.

9. Verina T, Kiihl SF, Schneider JS, Guilarte TR. Manganese exposure induces microglia activation and dystrophy in the substantia nigra of non-human primates. Neurotoxicology. 2011;32(2):215-26.

10. Zhao F, Cai T, Liu M, Zheng G, Luo W, Chen J. Manganese induces dopaminergic neurodegeneration via microglial activation in a rat model of manganism. Toxicol Sci. 2009:107(1):156-64.

11. Spranger M, Schwab S, Desiderato S, Bonmann E, Krieger D, Fandrey J. Manganese augments nitric oxide synthesis in murine astrocytes: a new pathogenetic mechanism in manganism? Exp Neurol. 1998;149(1):277-83.
12. Liu X, Sullivan KA, Madl JE, Legare M, Tjalkens RB. Manganese-induced neurotoxicity: the role of astroglial-derived nitric oxide in striatal interneuron degeneration. Toxicol Sci. 2006;91(2):521-31.

13. Streifel KM, Moreno JA, Hanneman WH, Legare ME, Tjalkens RB. Gene deletion of nos2 protects against manganese-induced neurological dysfunction in juvenile mice. Toxicol Sci. 2012;126(1):183-92.

14. Moreno JA, Streifel KM, Sullivan KA, Legare ME, Tjalkens RB. Developmental exposure to manganese increases adult susceptibility to inflammatory activation of glia and neuronal protein nitration. Toxicol Sci. 2009;112(2):405-15.

15. Filipov NM, Seegal RF, Lawrence DA. Manganese potentiates in vitro production of proinflammatory cytokines and nitric oxide by microglia through a nuclear factor kappa B-dependent mechanism. Toxicol Sci. 2005; 84(1):139-48.

16. Moreno JA, Sullivan KA, Carbone DL, Hanneman WH, Tjalkens RB. Manganese potentiates nuclear factor-kappaB-dependent expression of nitric oxide synthase 2 in astrocytes by activating soluble guanylate cyclase and extracellular responsive kinase signaling pathways. J Neurosci Res. 2008; 86(9):2028-38.

17. Chen CJ, Ou YC, Lin SY, Liao SL, Chen SY, Chen JH. Manganese modulates pro-inflammatory gene expression in activated glia. Neurochem Int. 2006; 49(1):62-71

18. Barhoumi R, Faske J, Liu X, Tjalkens RB. Manganese potentiates lipopolysaccharide-induced expression of NOS2 in C6 glioma cells through mitochondrial-dependent activation of nuclear factor kappaB. Brain Res Mol Brain Res. 2004;122(2):167-79.

19. Aschner M, Kimelberg HK. The use of astrocytes in culture as model systems for evaluating neurotoxic-induced-injury. Neurotoxicology. 1991;12(3):505-17.

20. Carbone DL, Popichak KA, Moreno JA, Safe S, Tjalkens RB. Suppression of 1methyl-4-phenyl-1,2,3,6-tetrahydropyridine-induced nitric-oxide synthase 2 expression in astrocytes by a novel diindolylmethane analog protects striatal neurons against apoptosis. Mol Pharmacol. 2009;75(1):35-43.

21. Li Z-W, Omori SA, Labuda T, Karin M, Rickert RC. IKK beta is required for peripheral B cell survival and proliferation. J Immunol. 2003;vol. 170:4630-7.

22. Zhuo L, Theis M, Alvarez-Maya I, Brenner M, Willecke K, Messing A. hGFAPcre transgenic mice for manipulation of glial and neuronal function in vivo. genesis. 2001;31:85-94.

23. Li W, Liu J, Hammond SL, Tjalkens RB, Saifudeen Z, Feng Y. Angiotensin II regulates brain (pro)renin receptor expression through activation of CAMP response element-binding protein. Am J Physiol Regul Integr Comp Physiol. 2015; Vol. 309:R138-47.

24. Livak KJ, Schmittgen TD. Analysis of relative gene expression data using real-time quantitative PCR and the 2(-Delta Delta C(T)) Method. Methods San Diego Calif. 2001;25(4):402-8.

25. Chang JY, Liu LZ. Manganese potentiates nitric oxide production by microglia. Brain Res Mol Brain Res. 1999;68(1-2):22-8.

26. Liddelow SA, Guttenplan KA, Clarke LE, Bennett FC, Bohlen CJ, Schirmer L, Bennett ML, Munch AE, Chung WS, Peterson TC, et al. Neurotoxic reactive astrocytes are induced by activated microglia. Nature. 2017:541(7638):481-7.

27. Xu J, Dong H, Qian Q, Zhang X, Wang Y, Jin W, Qian Y. Astrocyte-derived CCL2 participates in surgery-induced cognitive dysfunction and neuroinflammation via evoking microglia activation. Behav Brain Res. 2017; 332:145-53.

28. Liu W, Gao Y, Chang N, Nurr1 overexpression exerts neuroprotective and anti-inflammatory roles via down-regulating CCL2 expression in both in vivo and in vitro Parkinson's disease models. Biochem Biophys Res Commun. 2017;482(4):1312-319

29. Moreno JA, Streifel KM, Sullivan KA, Hanneman WH, Tjalkens RB. Manganese-induced NF-kappaB activation and nitrosative stress is decreased by estrogen in juvenile mice. Toxicol Sci. 2011;122(1):121-33. 